\title{
Identity Strategies of Muslim Meskhetians (Meskhetian turks) in Cultural Context
}

\author{
Ekaterine Pirtskhalava \\ Tbilisi State University, Tbilisi, Georgia
}

\author{
Lali Surmanidze \\ Tbilisi State University, Tbilisi, Georgia
}

\begin{abstract}
This study examines how the process of relocating has influenced on the strategy of identity of Muslim Meskhetians, the unique group from Georgia whit experiences of multiple forced migrations and displacements in the 20th and 21 st century. In the 40s of 20th century, as a result of Stalin's policy to clean the southern border of the Soviet Union from the "undesirable peoples", the Muslim population, primordially comprised of the Turkish-speaking Meskhetians, was deported from the Caucasus to the Central Asian republic of Soviet Union. The violent clashes in the Fergana Valley, Uzbekistan in 1989, Muslim Meskhetians have fled to Russia. After the fall of the Soviet Union in 1991, they lived in Russian Federation during 20 years without citizenship and any right. In 2005, the United States government granted refugee status to Muslim Meskhetians, and they moved to the USA. We combined the in-depth interviews with the immigrants, who live in the states of Pennsylvania and Illinois State of the USA, to illustrate the changes and effects of the relocation on the Muslim Meskhetian strategies of identity. Drawing upon theoretical conceptualizations of socialization and identity strategies of C. Camilleri, this study finds that Muslim Meskhetian immigrants are carefully negotiating strategy of identity in the face of displacement.
\end{abstract}

Keywords: displacement, Muslim Meskhetians, ethnic identity, negative identity, differentiating identity, addicted identity, Polemic identity, Reactive identity

\section{Introduction}

Displacement, as an act of moving of something from its place or position, has influenced the cultural and ethnic identity of many peoples. Bhurga (2004) notes: "When people migrate from one nation or culture to another they carry their knowledge and expressions of distress with them. The settling down in the new culture, their cultural identity is likely to change that encourages a degree of belonging; they also attempt to settle down by either being assimilated or bicultural". Camilleri (1996) admitted, when a person or a community changed location, style of life, and community the changes are reflected by the strategy of the identity of the people and the community.

Constructing identity is a cognitive process and as Moscovici's (1981) theory of social representations indicates, cognitive structures and processes come together and "knowledge structures are collectively shared, originating and developing via social interaction and communication" (Augoustinos \& innes, 1990). Howard (2000) emphasizes that "given an increasing emphasis on social processes, one may expect to see continuing

Ekaterine Pirtskhalava, Ph.D., assistant professor, Faculty of Psychology and Educational Sciences, Tbilisi State University. Lali Surmanidze, Ph.D., associate professor, Faculty of Psychology and Educational Sciences, Tbilisi State University.

Correspondence concerning this article should be addressed to 1a. Chavchavadze ave, TSU building 3, Tbilisi. 0179, Georgia. E-mail: ekaterine.pirtskhalava@tsu.ge. lali.surmanidze@tsu.ge. 
recasting of social schemas as more flexible and more grounded in social interaction" (p. 370).

The scholars (Camilleri \& Malewska-Peyre, 1996) admitted that the ethnic groups in the different social environments are using different identity tactics and strategies; strategies help them to engage or not in the social interaction with hosting society.

It should be noted that certain ethnic groups have a strong confidence about identity. The knowledge about similar hosting society is limited because of rules from host society. Continuation of preserving identity is possible only in limited perspectives and in resistant local conditions. And, maintenance of the identity in this process is possible through difficulties and resistance.

Our research has found a similar distribution of effects within a particular refugee Muslim Meskhetian ${ }^{1}$ community living in the United States. The Muslim Meskhetians originated from the south-west part of Georgia. The Muslim Meskhetians, have a unique history of multiple forced migration and displacement experiences.

The work of scholars (Trier et al., 2007) noted that it is possible everyday life and outlook can have an impact on new and different social environments, even in such a traditional society as that of the Muslim Meskhetians. Despite the fact that they are trying to maintain their values, customs and practice they are struggling against the impact of the new environment.

Contribution of this study to the field is to demonstrate the Muslim Meskhetians community's identity strategies in the U.S.A according to Cammileri's (1996) classification.

\section{Historical Background}

To understand the background of the Meskhetian issue, we need to review the history.

According to Georgian historical sources, a majority of Muslim Meskhetians are ethnic Georgians who were forced to live under the Turkish occupation from 1578 to 1883 . As a result, they transformed from Georgian-speaking Orthodox Christians to the Turkish-speaking Muslims.

During World War II, as a result of Stalin's social policy, the Muslim population were deported, predominantly comprised of the Turkish-speaking Meskhetians. There were 92,307 residents of five administrative districts of southern Georgia deported from the Caucasus to Central Asia (Kyrgyzstan, Kazakhstan and Uzbekistan), where they lived for approximately 45 years.

The conflict between local Uzbek and the deported Muslim Meskhetians in Fergana Valley (Uzbekistan) in 1989 left some Muslim Meskhetians without homes and as a result, they relocated to Russia. After the collapse of the Soviet Union in 1991, the Muslim Meskhetians became illegal citizens on the territory of the Russian Federation (Aydingün, 2002; Ossipov, 2007).

In 2005, the United States government granted a refugee status to the Muslim Meskhetians from post-Soviet Russia and this was their third displacement. In 2005, over 16,000 Muslim Meskhetians moved to approximately 33 states of the U.S.A (Koriouchkina \& Swerdlow, 2007).

Based on the acculturation and assimilation theory of Gordon (1964) and Berry (1997), the migrant society in homogeneously receives impacts of the new social and cultural environment. We agree with Bart (Barth,

\footnotetext{
1 The point of clarification: Some researchers refer to this population as to the Meskhetian Turks, or Turks from Meskhetia, but they call themselves as Ahiska Turks (which means Turks from Akhaltsiche—a main town in Meskhetia—a region in south west of Georgia). Throughout this study, I refer to this population as to the Muslim Meskhetians, because they are the deported Muslim population from Meskhetia.
} 
1969), who suggested that ethnic differences do not implicate unacceptability of each other and a lack of social interaction, on the contrary, quite often this difference becomes the foundation on which the whole social system is built.

Obviously, the life in the different socio-cultural space has the impact on the traditional Muslim Meskhetian society. These circumstances suggest that groups now live in different socio-cultural spaces, are generating the identity strategies according to that of the hosting community. At the same time, the Muslim Meskhetians are characterized by their typical identity strategies, which are applicable in all socio-cultural environments. Our research is devoted to the study of this issue.

This study expected that the displacement of the Muslim Meskhetians to the United States had the impact on their identity strategies in this different cultural context.

We suppose that, the fact that they have lived long in the collective cultural environment and they are the carriers of the collective cultural identity (Shakibai, 2005), moving to the individualistic cultural environment could have an influence on different aspects of their lives and could have given an impulse to develop the new identity strategies (Cammileri, 1996).

\section{Methodology}

In this research, we followed the general approach of immigration scholars who proceed from the premise that to understand the depth of the immigrants' experiences and sentiments in the new environment and to capture how they assimilated, acculturated, integrated and adapted, qualitative methods can provide more reliable and multifaceted data (Kim et al., 2001).

This result is a part of the study which was carried out in two stages. After reviewing the results of the first stage was conducted in 2012, in which the Muslim Meskhetian communities in Pennsylvania participated, an idea to study their identity strategy in the new environment has emerged. This stage involves the second researcher, and they jointly developed a new guide for the new study.

Based on recommendations for selecting the sample size in qualitative research (Creswell, 1998), I conducted 30 qualitative in-depth interviews with the members of the Muslim Meskhetian communities in Pennsylvania (March-April 2012) and Illinois, as well as group interviews with the Muslim Meskhetian communities in Illinois (February 2014).

The participants of 3 group interviews were: - 6 women (from 17 to 24 years old); - 6 men (from 25 to 29); - 4 adult men (from 47 to 60 ).

Table 1

Distribution of Respondents of Interview by Age $(N)$

\begin{tabular}{llllllllll}
\hline Gender & $\mathrm{N}$ & \multicolumn{3}{c}{ Age } & \multicolumn{2}{c}{ Education } & \multicolumn{2}{c}{ Marriage } \\
\cline { 2 - 9 } & $\mathrm{N}$ & $20-29$ & $30-45$ & $46-62$ & School & Voc/Tr/Un in USSR & College & Married & Unmarried \\
\hline Female & 14 & 5 & 7 & 2 & 9 & & 3 & 11 & 3 \\
Male & 16 & 4 & 2 & 10 & 10 & 6 & & 13 & 3 \\
Total & 30 & 9 & 9 & 12 & 19 & 6 & 3 & 24 & 6 \\
\hline
\end{tabular}

The interviews were conducted in Russian and were audio recorded and later transcribed in the campuses of Rutgers University, New Brunswick, NJ, and the University of Illinois, Urbana-Champaign. The interview protocol included open-ended questions, a guideline was conducted according to the content of the identity strategies tipology. 
Based on the analyses of the indephs and group interviews and participant observation, we can share our findings.

\section{Analysis and Discussion}

Our respondents were faced with a double difficulty: on the one hand, they represented an ethnic minority (non-dominant) group in all socio-cultural spaces following deportations, and on the other hand, they as "third world" representatives found themselves in the United States - in a country having an industrial dominance.

Thus, they found themselves in an environment where traditional and modernist cultural codes clashed with each other and where, pragmatic functions of identity inevitably become a subordinate to perceptions and values determined by "modernist" codes. In conditions of non-positive relations and asymmetry between groups, a categorizing aspect in human relations comes to fore. Also, an impact of asymmetry on identificative actions is constant. The identification mechanisms of our respondents have been established in these circumstances.

Respondents reported that they were ascribed negative values in Russia, where humiliating, more or less stereotypized images about the group were widespread. Their assessment made by those who were in dominant situations turned out to be so crucial for the self-identification that even the diminishing image was considered as an objective reality. This is an apparent "negative identity", when a subject determines its value according to what "other" has ascribed to it.

For example, in Russia, in the Krasnodar region, where our respondents were in the disadvantageous social position, they were called as "blacks", "chornazhopie" (in Russian-черножопые- having black ass). This ascribed diminishing identity was so interiorized that when filling out the US visa application, they placed themselves in the box "black" and as they said, realized that they were white skinned only after the explanations of their host.

Our study has not revealed "a conveyed negative identity", the essence of which is that a human being free from the interiorization of humiliating judgments identifies himself/herself to someone being in an advantageous position or transfers depreciating characteristics to other members of his/her ethnic group. But these people very actively use the so-called "differentiated identity" strategy, which is manifested in a tendency to create distance with the indigenous (autochthons) on the basis of understanding their own characteristics. An important component of this strategy is to consider themselves and their own ethnic group as supporters. Thus, the conflict with such indigenous (autochthons) takes place by raising the "we" construct to the foreground, while the core of the "we" constructs are typically formed by the positive content of the traditional dominance:

We have all the good. We are hospitable, honest and hardworking, respectful to the older generation of the family and the parents, as well as to each other, we help one another, and teach our children how to behave. (53-year-old man, married)

One of the essential components of their differentiating identity is a religion and adherence to the rites and customs common in Muslim Meskhetian families. A traditional "dominant" is clearly expressed:

Families shall live in an extended form; an old man shall be a head of the family; Youngers shall adhere to and do what the elders say without words; a woman shall be obedient and wear a headscarf at home; it is necessary to speak Turkish at home.

An aspiration to increase a distance with the indigenous (autochthon) ns by highlighting differentiation was well reflected in the position of one of our respondents: 
We are not interested in a relationship with them, so we communicate less. People who are close to us are our relative relations with them are enough. Locals have different mentality they do not understand us. This is a problem of mentality, not a language barrier. (48-year-old man, married)

"The differentiating identity" also manifests itself in giving a priority to compact housing settlements:

We try to settle together, to live near, have contacts with each other, nobody invites us, we visit each another, and we cannot live without each other. (53 year-old man, married)

This way the subject goes beyond the space of the "addicted" identity, from manipulating its identity by others.

This group in other countries also actively applies "The differentiating identity" as a strategy. For example, they consider that they differ from Russians with the religion, the upbringing style and family strength.

The Russians are drinking and are beating their wives, but we respect each other and treat our family members respectfully. (56-year-old man, married)

They list characteristics of the modern world as distinctive aspects making them different from the Americans: mixed marriages, more independence for children from an early age, a low conformism level of the younger generation, a different upbringing system, etc.

Our data revealed an existence of the "polemic identity", which is the extreme form of the "reactive identity". We will again repeat its essence: Persons being in the disadvantageous social position openly reveal polemical mood regarding the identity ascribed to them by the dominant group.

The following constructs are underlined in the pillar auto-stereotype of this strategy: "hard-working", "honest", "law-abiding" and "loving family and traditions". As they say, when we lived in Meskheti and Uzbekistan, "we revived these places, Uzbeks envied us", "we were making land in Russia beautiful", "US sheltered our people in order to cultivate uncultivated lands and revive these places", "let's them allow us to Georgia and we will make this country to flourish", etc.

This is a typical manifestation of such identity-reactions, the aim of which is not to reflect a reality, but rather to release those negative evaluations in which they lived. It is therefore understandable the exaggeration of their ethnic group's positive qualities, which we observe here. But in its essence, this is a defence mechanism.

Our research did focus on learning strategies of releasing the identity from conflicts, although it is possible to describe some of the trends based on our database. In particular, we most commonly find the strategy of release from identity conflicts using a "simple coherence" method (strategy): "I" is totally invested in the traditional system and completely rejects the modernist. It characterizes mainly the elderly people, but other age perspectives are also frequent. "The simple coherence" strategy is manifesting itself in a so called "game", as the subject remains in the traditional system, but reveals certain acceptance of the elements of the rejected model.

For example, as women reported, with their husbands' permission, they can walk in streets without headscarf, although in the "inner space" (with older people, at visits and with strangers) they unconditionally fulfil the traditional requirements. Our respondents indicated that at the ritual meetings (funerals, weddings, etc.), men's clothing does not matter, but women's clothing should be placed under the framework of women's traditional clothing (the dress shall have long sleeves, married woman shall be covered). 
It should be noted that the priority of the pragmatic function in the identity is already observed regarding the issue related to women's education. For example, as one of the respondent said,

I would rather prefer my daughter not to marry early and instead to receive an education. When she marries, she will have children and will not be able to distribute time for learning. So it would be better first to learn and then to marry. (47-year-old man, married)

Marriage within the ethnic group is still preferred.

Here in the USA we only marry inside our group, we do not marry people of other nationalities. (33-year-old woman, married)

Although some deconstruction of this position and development of so called complex coherence can be observed when signs of both codes are merged.

When we choose a wife, the family consent is important, the nationality or religion does not matter. If you fall in love with an American, what's the problem, you marry the American if the family agrees to it. (a 25-year-old man).

\section{Conclusions}

Our study revealed that the identity strategies described in the Camilleri classification are working within the Muslim Meskhetians, and they are characterized by: the negative identity, the reactive identity (i.e. distinctive reaction) and polemical identity (the most extreme form of the reactive identity). We also revealed that in the process of overcoming identity conflicts, the simple coherence strategy is clearly expressed, but the elements of complex coherence strategy are also observed in a part of the young Muslim Meskhetians.

We observed that the complex coherence strategy to overcome the cultural identity conflict was revealed via the typological codes, namely, in the form of the synthesis of individual characteristics of individualistic and collectivist cultures.

Collective cultures, especially representatives of vertical collectivism and as our target group is, are characterized by an active participation of referent groups in marriages. In our opinion, tendencies reflected to the choice of a marriage partner, as well trends related to the child-rearing model can be considered as having influenced by the American individualistic culture of life.

Unlike the elderly respondents, a part the young survey participants considers selection of the marriage partner from the exogenous group permissible, furthermore, they even accept cases of having a different religious faith. However, when making this kind of decision-making, they still consider an approval of the family as a necessary precondition of such marriage (so called the liberated conformity effect); it should be underlined that men are holders of this opinion.

The second case is related to child-rearing models: The survey participants think that child-rearing practices should be modified according to the requirements of the new environment, for example, the children shall be able to express their opinions freely, the head shall be respected and their opinions shall be taken into account, but independent decisions shall also be taken, and so forth.

Thus, our research has also confirmed the position of the researchers of the identity strategies (Camilleri \& Malewska-Peyre, 1996) who suggested that representatives of the same ethnic group in different socio-cultural fields may apply different identity strategies.

We consider that it is interesting to further research the identity strategies of the Muslim Meskhetians in other countries, particularly in their homeland Georgia, where a small part of the Muslim Meskhetians has been 
living since their repatriation in 1980, as well as in Azerbaijan, where Muslim Meskhetians repatriated after the 1989 conflict.

\section{References}

Augoustinos, M., \& Innes, J. M. (1990). Towards an integration of social representations and social schema theory. British Journal of Social Psychology, 29(3), 213-231.

Aydingun, A. (2002). Creating, recreating and redefining ethnic identity: Ahıska/Meskhetian Turks in Soviet and Post-Soviet contexts. Central Asian Survey, 21(2), 185-197.

Berry, J. W. (1997). Immigration, acculturation and adaptation. Applied Psychology: An International Review, 46(1), 5-68.

Bhugra, D. (2004). Migration, distress and cultural identity. British Medical Bulletin, 69(1), 129-141.

Camilleri, C., \& Malewska-Peyre, H. (1997). Socialization and identity strategies. In J. W. Berry, P. R. Dasen, and T. S. Saraswathi (Eds.), Handbook of cross cultural psychology: Vol. 2 basic processes and human development (2nd ed., pp. 41-67). Needham Heights, MA: Allyn \& Bacon.

Creswell, J. W. (2009). Research design: Qualitative, quantitative and mixed methods approaches. (3th ed.). Thousand Oaks, Calif: Sage Publications.

Barth, F. (1969). Ethnic groups and boundaries. The social organization of culture difference. Oslo: Universitetsforlaget.

Barth, F. (2006). Introduction. In F. Barth (Ed.), Ethnic groups and social boundaries: Social organization of cultural differences (pp. 9-49). New Publishing.

Howard, J. (2000). A social psychology of identities. Annual Review of Sociology, 26, 67-93.

Kim, B., Yang, P. H., Atkinson, D. R., Wolfe, M. M., \& Hong. S. (2001). Cultural value similarities and differences among Asian American ethnic groups. Cultural Diversity and Ethnic Minority Psychology, 7(4), 343-361.

Koriouchkina, E. (2011). Contingent Ethnicity in State(s) of Change: The Journey of Meskhetian Turks from the USSR to the Post-Soviet World (Doctoral thesis, University of Brown, RI).

Koriouchkina, E., \& Steven, S. (2007). The third migration: Meskhetian Turks in the United States. In T. Trier and A. Khanzihn (Eds.), Meskhetian Turks at a crossroads: Integration, reparation or resettlement (pp. 378-435). Berlin, Germany: Lit Verlag.

Gordon, M. M. (1964). Assimilation in American life. The role of race, religion,and national origins. New York: Oxford University Press.

Moscovici, S. (1981). On social representations. In J. P. Forgas (Ed.), Social cognition:Perspectives on everyday understanding (pp. 181-209). London: Academic.

Ossipov, A. (2007). Falling between the cracks: The legal status of the Meskhetian Turks in the Russian Federation. In T. Trier and A. Khanzihn (Eds.), Meskhetian Turks at a crossroads: Integration, reparation or resettlement (pp. 435-486). Berlin, Germany: Lit Verlag.

Shakibai, S. (2005). An examination of collectivist cultural orientation among Middle Eastern college students of different gender generation status and academic class standings (Unpublished thesis, University of Maryland, College Park, Md.).

Trier, T., \& Khanzhin, A. (Eds.). (2007). The Meskhetian Turks at a crossroads: Integration, repatriation or resettlement. Berlin, Germany: LIT Verlag: Berlin. 